\title{
THE IMPACT OF MOBILE MONEY TRANSACTION EFFICIENCY ON THE SUPPLY CHAIN PERFORMANCE OF SMALL SCALE COCOA FARMERS IN GHANA
}

\author{
Yinfei Chen ${ }^{1}$, Kelvin Darkwa ${ }^{2}$ \\ ${ }^{1}$ School of Finance and Economics, Institute of Industrial Economics, \\ Jiangsu University, Zhenjiang, China \\ ${ }^{2}$ School of Finance and Economics, Department of Applied Economics \\ Jiangsu University, Zhenjiang, China
}

Article DOI: $\underline{\text { https://doi.org/10.36713/epra8213 }}$

DOI No: 10.36713/epra8213

\begin{abstract}
Purpose- the reason behind this work is to fine out the rising service of Mobile Money Transaction which offers banking services to all manner of persons only if they hold a phone can impact the biggest economy of the country Ghana thus agriculture which in this sector cocoa production in the country.

Design/methodology/approach- the paper draws literature from numerous studies that relates to the subject of discussion. 204 questioners were designed and administered out of which 204 was correctly answered by small scale cocoa farmers and used for the analysis of this paper. Spss, excel and Smart Partial Least Square 3.0 was used in analyzing the data.

Findings - Mobile Money Services has a strong service quality and thus impact transaction efficiency of the service positively. The transaction efficiency of the Mobile Money services also has a strong impact on the supply chain performance of the small holder cocoa farmers.

Research limitations/implementations- the educational level of most of the respondents were low thus finding it difficult to read and understand. Researcher had to break things down and answer on their behalf. There is no clear laydown procedure for the supply chain of cocoa farmers. Most respondents live in the remotest part of the villages.

Originality and value-there are so many papers on mobile money but no studies have been able to link the transactional efficiency of the service to agricultural supply chain.
\end{abstract}

KEY WORDS- Mobile money services, supply chain performance, transactional efficiency, mobile money service quality Paper type- Research

\section{INTRODUCTION}

About 2.2 billion citizens in the globe lack access to a traditional bank account. Many low income countries including Ghana, especially in rural regions which are dominated by small scale farmers do not have access to formal financial services. (Sarah Yu and Samia Ibtasam 2018)

Farming and the agricultural business experiences several challenges, predominantly with respect to affordable access to finance. Commercial banks and financial institutions have been unwilling to offer financial services to agricultural business for the reason perceived to be sector-specific risks, transaction costs. (The World Bank 2016)

The arrival of rural micro-finance institution, Saving and Credit Cooperative Societies, rural banks and even Agricultural banks (in the case of Ghana) has stood on the basis that smallholder farmers need exclusive services that are near to them. Yet all these banks expected to operate in the rural certain have moved to the urban centers. These preceding factors limit the ability of smallholder farmers (rural settlers) to save, borrow as well as access payments: High operation costs of providing services by banks, widely scattered farmers, high covariate threats, weather and 
market risks and the lack of suitable collateral by farmers. (Poulton et al., 2006, Okello et al., 2010).

The aspiration to shoot progress in smallholder agriculture has generally led to examining of new replicas of agricultural financing that solves this problem faced by small holder farmers. A report from Donovan (2012) established that Mobile money is an economical means of extending traditional banking to the unbanked via the mobile phone; which is a medium they are already conversant with.

92 countries within the world having more than 174 million registered account that are active within the year 2017 having 276 mobile money services for those denied financial services and over 44 million unregistered over-the-counter users Mobile money is now available in two thirds of low- and middle-income countries. Vodafone alone exported the M-Pesa system to Afghanistan (2008), to India (2013), to Europe (Romania in 2014 and Albania in 2015), and to many countries in Africa. Mobile money refers to financial transaction services potentially available to anyone owning a mobile phone, including the unbanked global poor who are not a profitable target for commercial banks (GSMA, 2016).

Mobile money applications are typically small pieces of software embedded on a SIM card or available over a mobile network. A customer can use an inexpensive mobile to send value to someone else. To change this digital value into cash, a user simply visits a retail agent who verifies the user's identity and makes the switch. In this way, money can cross-enormous distances at the speed of a text message. Consider a young Ghanaian who has moved from Kumasi to Accra to find work. With mobile money, he can send regular, small payments to his family at their rural home without needing to pay and trust a courier or take it himself. His family can then exchange the digital value for cash at a local agent. (Kevin Donavan, 2016)

For the first time Momo as a financial inclusion has captured lots who remained unbanked into the banking and formal financial sector. (B\&FT, 2018)

It is based on this inclusion of financial activities of small scale farmers (unbanked) by mobile money services that this paper seeks to find out how the efficiency of this new financial instrument is impacting the participants of the supply chain.

\section{CURRENT SITUATION OF THE PROBLEM}

MTN Ghana Limited first presented Mobile Money in Ghana in the year 2009. Four out of the sixtelecommunication companies (telcos) in Ghana (Quist, 2015) currently runs Mobile Money. Abbey (2016) recounted that, the permeation of Mobile Money in the Ghanaian economy has improved meaningfully in the preceding years, since its inception in 2009. In 2016, mobile money transactions amount to 35.4 billion Ghana Cedis; signifying a boost of more than 216 percent paralleled to the overall operations of more than 260 million in 2015. This also signifies an escalation of over twenty percent (20\%) of mobile money permeation in Ghana. Konutsey, (2016) demonstrations that, the World Bank Findex data declares Ghana as unique of 13 economies which had Mobile Financial Services (MFS) diffusion exceeding $10 \%$ in 2014. On the other hand, Blay (2016) contends that according to stakeholders in the telcos and financial industries, although there is substantial increment in Mobile Money Transactions, further unbanked Ghanaians must be provided financial inclusion seeing the fact that Ghana's Mobile Money Penetration of $20 \%$ is small likened to Mobile Money penetration in East African countries.

\section{THEORETICAL FRAMEWORK AND HYPOTHESIS DEVELOPMENT}

Figure 1-Cocoa Supply Chain

Information

\begin{tabular}{|c|c|c|c|c|c|c|}
\hline $\begin{array}{l}\text { Agric } \\
\text { Farm } \\
\text { input }\end{array}$ & $\begin{array}{c}\mathrm{S} \\
\text { Farm } \\
\text { production }\end{array}$ & $\begin{array}{c}\text { Post } \\
\text { harvest }\end{array}$ & $\begin{array}{c}\text { Storage } \\
\text { and } \\
\text { Transport }\end{array}$ & $\begin{array}{c}\text { local } \\
\text { buying } \\
\text { agent }\end{array}$ & $\begin{array}{c}\text { cocoa } \\
\text { buying } \\
\text { companies }\end{array}$ & EXPORT \\
\hline \multicolumn{7}{|c|}{ Material } \\
\hline \multicolumn{7}{|c|}{ Capital } \\
\hline
\end{tabular}


Agricultural farm inputs are any external source put into soil that can help a farmer's upcoming yield. They can be anything from high-quality seeds to high-tech tractors. Simply put, they're any resource you use to increase your crop's success.

Farm production deals with the entire process of farming until harvesting

Post-Harvest deals with the processing thus addition of value to cocoa beans to make it readily available for retailing in this case depoding and drying of cocoa beans

Storagesand transportation talks of all involvement of transportations and storing of processed cocoa beans

Local buying agents popularly called cocoa krakye are people that buy processed cocoa beans in bits from smallholder farmers, gather them into larger quantities and wholesale to cocoa buying companies.

Cocoa buying agents are companies buy buys processed cocoa beans in bulk from cocoa agents and exports them from the country.

\section{Transactions efficiency}

Transaction efficiency refers to the transaction process - minimizing the waste of time, effort and money in the interactions between the parties and their advisors. It is built around organization and effective communication, and offers the additional benefits of reduced confusion and aggravation. A transaction process that is not efficient is wasteful and frustrating.

\section{The efficiency of Momo on the participants of the supply chain of cocoa farmers}

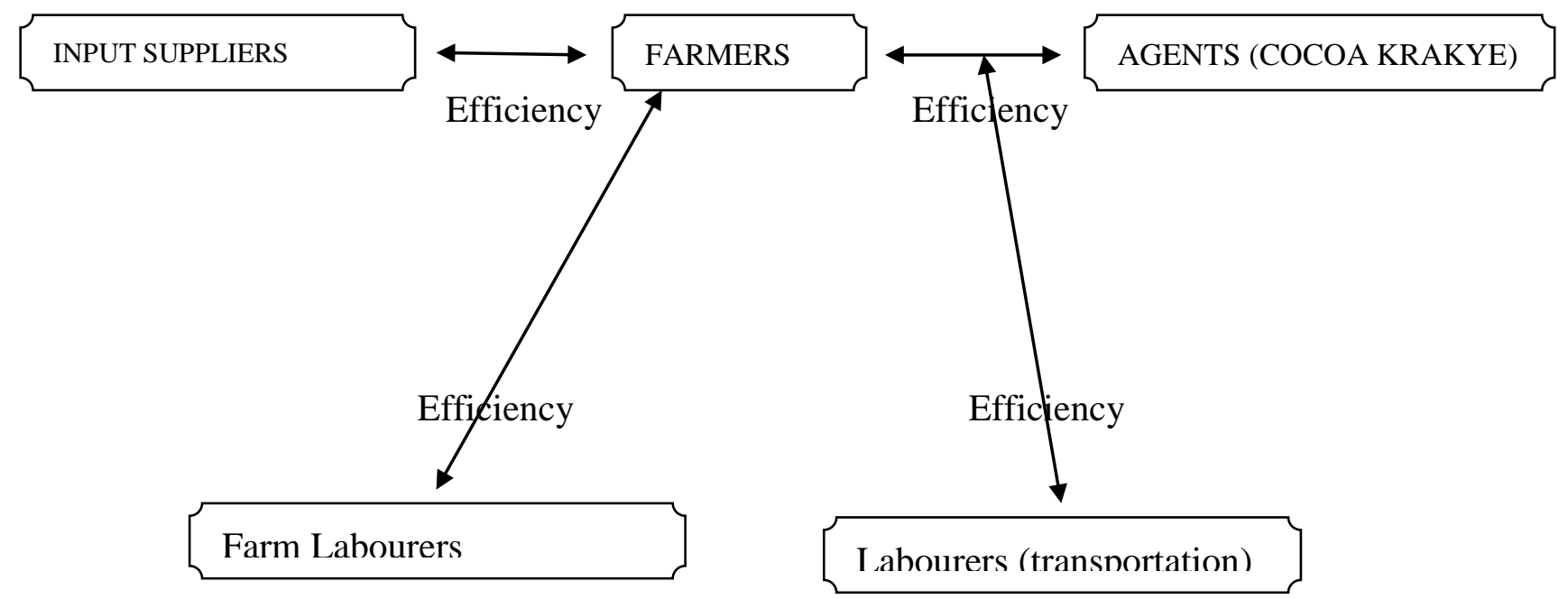

Figure 2- Transactional efficiency among cocoa supply chain

\section{Why does "transaction efficiency" matter?}

Transaction efficiency leads to faster transaction completion, improves interactions between the transaction parties, and reduces the time, effort and money spent on the transaction. Complex transactions involve significant levels of professional services, and these costs are generally a function of time. At the extreme, in a transaction that is so inefficient that major mistakes occur, even the "effectiveness" of the transaction can come into question. Transaction Commons, 2019
Mobile Money Services and Transaction Efficiency Mobile Money Transactions (popularly known in Ghana as MOMO) is the term used to describe the manner in which one sorts out payments with others via the usage of a cell phone where the worth of the currency can be deposited on a "mobile wallet" before and after the operation. A sender loads money into his mobile wallet via going to an accredited agent from his network operator. The sender can use a secure automated method to send moneys to the receiver's momo wallet. The receiver will get a text message that he can show to an agent to receive the money in cash. 
The receiver can either keep the money sent in his momo wallet for later mobile money operations or go to an agent to exchange the mobile money to solid currency. (USAID 2010)

The rapid, early success of M-PESA in Kenya led some to predict that low-cost, digital financial services would quickly spread throughout the developed and developing world. M PESA reached one million active mobile money accounts in 2008 (GSMA, 2016)

Moving forward challenges connected with bank and non- bank transfer platforms, consist of joining time-consuming queues, local office network failures, liquidation of bank and allocation of bank branches, undependable communication canals and many more. This circumstances has transformed intensely in the latter few years by the institution of Mobile Money transfer services (Mutinda, 2014)

With an enormous network of Mobile Money Services agents throughout the country, it makes it more relaxed for agrarian households to lessen the time and cash expense in accessing the moneys they require to invest in agriculture.

H1: Mobile money services is efficient in the operations of farmers activities

\section{Transaction Efficiency and Supply Chain Performance}

An efficient vs. responsive supply chain is a common dilemma. Let's begin with efficiency. There is rarely the case where efficiency is a bad thing. Efficient processes result in less waste. Efficient workflows result in greater productivity. What about an efficient supply chain? Supply chain management by definition is efficiently managing the flow of goods and service to ultimately provide something of value to the customer at the lowest possible cost to do so.

The supply chain consists of many moving parts, each of which must execute their role near perfectly in order for the entirety of the supply chain to be efficient. That means every supply chain stakeholder needs to have efficiencies built into their business processes and operations, from innovation to manufacturing to logistics. If one area is off, the whole supply chain is affected. (Henry, 2020)

H2 : Transactional efficiency helps to improve supply chain performance

\section{RESEARCH FRAMEWORK}

The efficiency of mobile money services throughout the participants of the supply chain will help cocoa farmers increase outputs and thus increases their profits.

\section{(Variables)}

Figure 3 - structural model

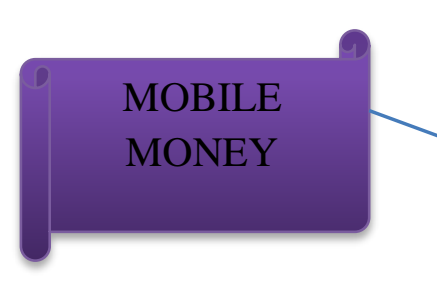

\section{DEFINITION OF VARIABLES}

This mechanism used the structural education model to handle the components. Mobile money thus independent variable will be measured using the servequal model with sub variables being (reliability, empathy, responsiveness, tangibility and assurance) to find out its impact of transactional efficiency the dependent variable which also was measured using variables such as (cost, effort, timeliness and safety)

Transaction efficiency being the dependant variable using the linear regression according to this model was done to fine out its impact on Supply Chain Performance of the cocoa supply chain of small holder farmers. Supply chain performance in this study uses the supply chain measurement variables thus (cost, material availability and schedule changes) 


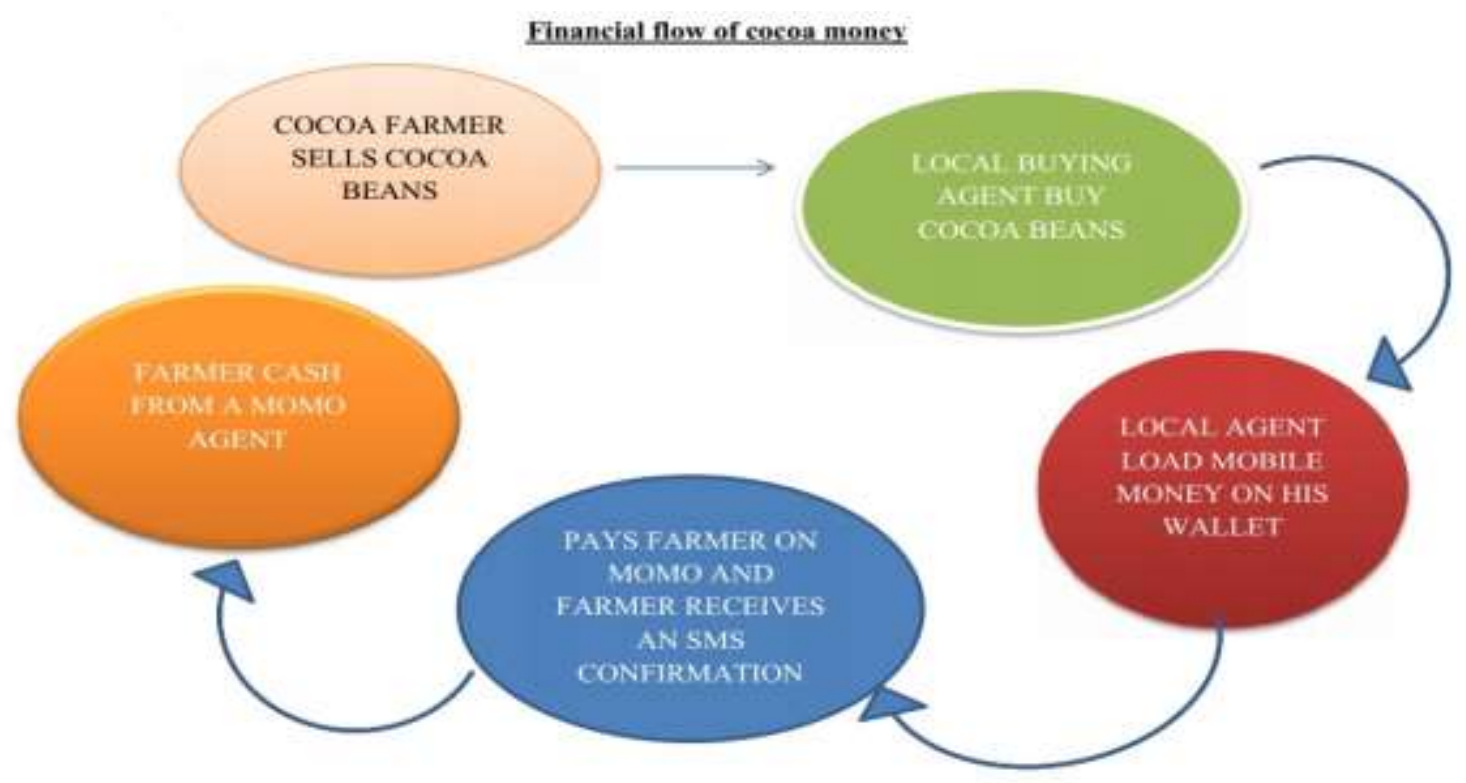

Figure 4- Momo financial flow among the supply chain

\section{METHODOLOGY}

\section{Research Design}

This study employs three resign design techniques. That is descriptive, questioner base survey and experiment. The question base employed a well structured questioner to gather primary date for analysis. The descriptive survey will analyze also the transactional efficiency of mobile money services in the supply chain of the participants of cocoa production.

\section{Source of Data}

The study employs and makes use of both primary and secondary data. Primary data is taken from the key actors or focus of the study who are farmers, cocoa buying agencies, transport operators, input suppliers through the administration of a wellstructured interview.

Secondary data is sourced from the Cocoa Marketing Company responsible for cocoa production in the country. Data concerning mobile money transactions, supply chain, cocoa agricultural activities with all statistics in the review of literature, introduction, current trend of issues concerning the study were all taken from journals, periodicals, MOFA, FAO, as well as news items from media houses in the country.

Techniques and Methods of Data Collection

250 close-ended questionnaires were administered through a face-to-face interview since majority of these small-scale farmers lack basic education.

\section{Method of Data Analyses and presentation}

The data will be analyses descriptively using frequencies whereas partial least squares structural equation modeling (PLS-SEM) technique using the SmartPLS 3.0 software was used for the factor analysis.

\section{FINDINDS AND DATA ANALYSIS Introduction}

This part deals with the findings of the research. The findings were gotten from the response of questionnaires on Momo service quality, transactional efficiency and supply chain performance of Momo among small holder cocoa farmers. Smart PLS, Statistical Pack for Social Scientist (SPSS) and Microsoft Excel was used in analyzing the data, and table is used to reflect the frequencies or magnitude of the responses.

\section{RESULTS FOR MOMO SERVICE QUALITY DIMENSIONS}

Table 1 indicates a descriptive frequency statistics of Momo service quality variables using the standard deviation and mean calculated using spss for the overall questionnaire of 204 respondents for each service dimension of service quality. The table below shows variables that are good or worse using the lower bound. The higher the lower bound figure the better the quality of the variable used as indicated by Abango.

The lower bound has been calculated at $95 \%$ confidence interval level. Standard deviation $(\alpha)$ gives 
an implication of how far the individual feedbacks to a question vary or "deviate" from the mean. Standard deviation $(\alpha)$ actually tells that the respondents rated the questionnaire variedly. The distribution of the answers is considered significant since the $\alpha$ gives good descriptive measures of the spread.

Table 1

\begin{tabular}{|l|c|c|c|}
\hline $\begin{array}{l}\text { MOMO } \\
\text { SERVICE } \\
\text { QUALITY }\end{array}$ & $\begin{array}{c}\text { Mean } \\
{[\mathbf{X}]}\end{array}$ & $\begin{array}{c}\text { Std. Deviation } \\
{[\boldsymbol{\alpha}]}\end{array}$ & Lower Bound \\
\hline RELIABILITY & 4.43 & .620 & 4.35 \\
EMPATHY & 4.22 & .923 & 4.09 \\
TANGIBLES & 4.53 & .815 & 4.42 \\
RESPONSIVE & 3.51 & .934 & 3.39 \\
NESS & 4.47 & .623 & 4.38 \\
ASSURANCE & & & \\
\hline
\end{tabular}

From the table it is evidence that Assurance has the highest figure of 4.38 in the lower bound measurement, this means that assurance has the highest significance quality dimension level in Momo service quality, reliability is next significant in affecting quality level with a lower bound of 4.35, however responsiveness has the least lower bound with a value of 3.39, this implies it is less significant in service dimensions that affects service quality of mobile money services.

\section{Mobile money service quality, transaction efficiency of mobile money services and supply chain performance}

Figure 5- Structural Equation Model

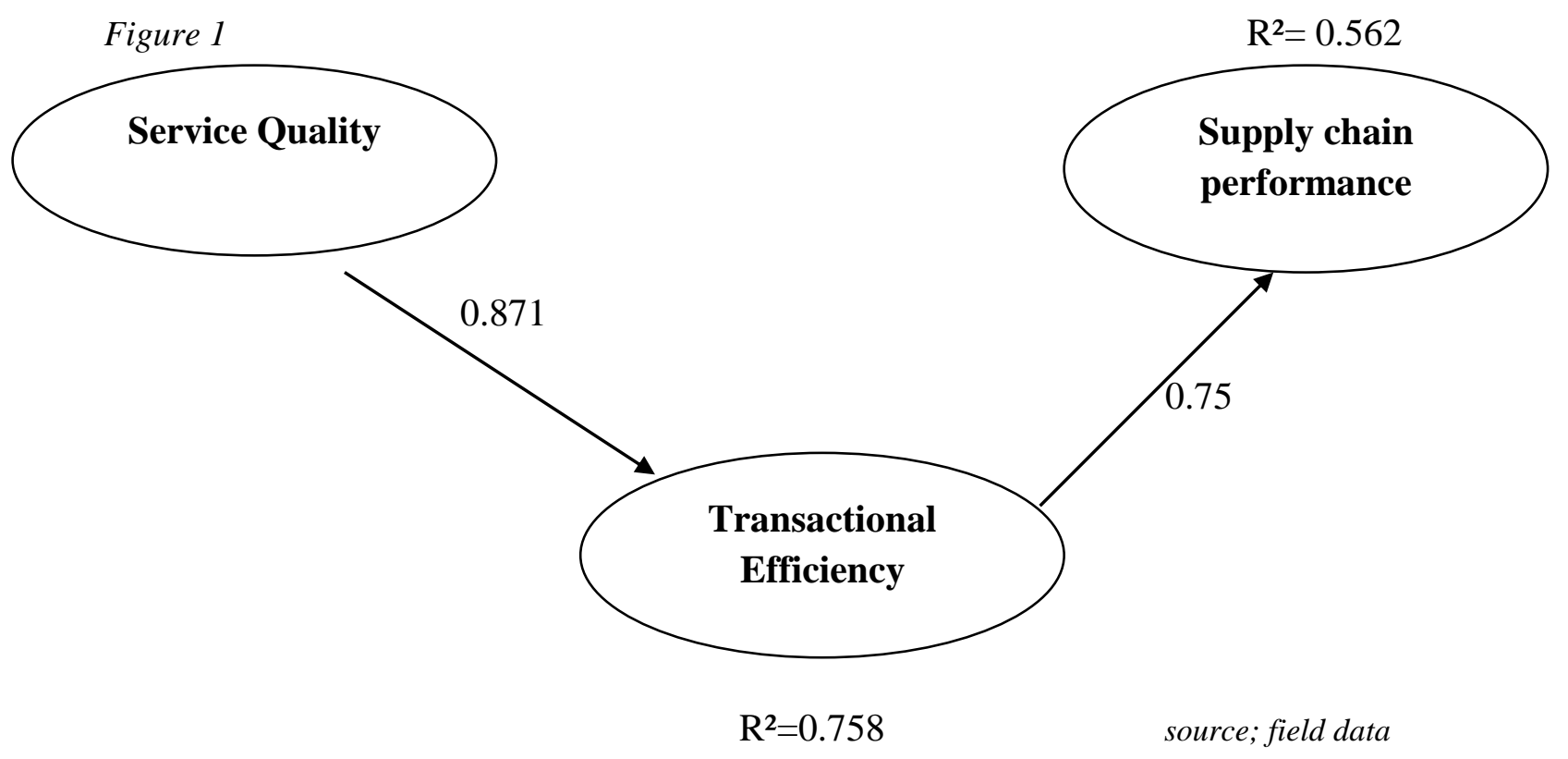


The Impact of Service Quality and Transactional Efficiency of Momo Service

From figure 1, the model is fit for analysis as the overall test of significance (t-stats) fits the data of pvalue $<0.05$ making the model acceptable for analysis. Momo Service Quality (MSQ) being the independent variable has an impact of the Transactional Efficiency (TE) of the Momo service.

From the model, a percentage increase in MSQ will cause an expected rise to the TE of THE Mobile Money Service (Momo) by $87.1 \%$. it is well denoted again from the figure $2, \mathrm{R}^{2}$ which has the value $75.8 \%$ of the TE can be explained by MSQ.

Thus there is a positive relationship between service quality and transactional efficiency of Mobile Money Services

\section{The Impact of Transactional Efficiency on Supply Chain Performance}

Analyzing the impact of TE on Supply Chain Performance (SCP) was done using a linear regression model. The model is fit for analysis as the overall test of significance (t-stats) fits the data of p-value $<0.05$ making the model acceptable for analysis.

From the model in figure 2, it can be noted that, a percentage rise in transactional efficiency of the operations of Momo will cause an expect rise of $75 \%$ in the performance of the supply chain of the small holder cocoa farmers. Small holder cocoa farmers supply chain has a positive relationship with mobile money transactional efficiency.

Thus accept null hypothesis that the performance of the supply chain can be improved by the efficiency of Momo

\section{CONCLUTIONS AND RECOMENDATIONS}

The function of mobile phones in today's communication has thoroughly brought changes to the way Ghanaian farmers communicate, receive information and support decision making. Mobile Money services which most of the farmers are hook on to provide financial support to assist the operations of the farmers.

The Way Forward for Mobile money transaction in Ghana

With the greater than before number of cell phone users in Ghana, and the huge number of the unbanking population in Ghana, Mobile money transaction, which provide people the opportunity to send, receive and save money on their sim card fixed in their cell phones, is the new development in payments systems globally. Given the consciousness level of momo among the respondents of the questionnaire undertaken as part of this project, there is a tremendous opportunity for mobile phones to be used as a payment system in Ghana, provided that users are educated about momo, ensure adequate security infrastructure, and address charging related issues.

\section{Education}

The illiteracy rate in among small holder cocoa farmers in Ghana is huge and so is the number of people who has no access to formal financial services as well. This means that for Momo to catch on in Ghana intensive education needs to be undertaken to educate people (both literates and illiterates) about what Momo is, how it works and most importantly on how to use it.

\section{Security}

During interaction with most of the respondents of the questionnaire, one of the questions that came across over and over again is Security. Momo systems should be friendly to use, but very secured as much as possible to increase people's trust in the system. Since hackers are now using dubious means to redraw other savings.

\section{Charges}

During interaction with most of the respondents of the questionnaire, another question that came across was on Charges. They were concerned about the fee charges that come along with using momo services. They want it to be free. Therefore, for momo to catch on in Ghana, more Merchants should come on board to bear most of these charges, to increase the usage of momo services in Ghana.

\section{LIMITATION OF THE STUDY}

The illiteracy rate of Small Scale Farmers in Ghana, the unwillingness of some farmers to reveal some secretes on their finances, lack of proper agricultural supply chain channel of small Scale Farmers, and might have impacted on the findings.

There might also be dishonest and deceptive responses to satisfy the researcher. Notwithstanding, the study was effectively carry out due to the creativity and hard work of the researcher. Efforts were put in place to reduce these effects on findings. some of these effects includes a face to face administered questionnaire to ask and record on their behalf as well as understanding the supply chain of these farmers and designing a clear one for them to suit the purpose of this study in reflecting the issues on the ground. 


\section{REFERENCES}

1. Sarah Yu and Samia Ibtasam 2018, A Qualitative Exploration of Mobile Money in Ghana Paul G. Allen School of Computer Science \& Engineering University of Washington sarahyu@cs.washington.edu

2. The World Bank 2016, Financing Agribusiness in Sub-Saharan Africa: Opportunities, Challenges, and Investment Models. The World Bank Group,1818 H Street, NW Washington, DC 20433 http://www.worldbank.org

3. POULTON, C., J. KYDD and A. DOWARD (2006):

Overcoming market constraints on pro-poor Agricultural growth in sub-Saharan Africa. In: Development Policy Review 24 (3):243-27.

4. Donovan, K. (2012). Mobile Money for Financial Inclusion (1st ed., p. 63). GSMA Mobile Money Tracker 2012

5. GSMA Intelligence, 2016. Available at: https://gsmaintelligence.com/ Success factors for mobile money services A quantitative assessment of success factors.

6. Konutsey, S. (2016). Economics of mobile money and financial inclusion: Bank of Ghana at the forefront of regulations. Ghana News. Retrieved 20 March 2017, from http://citifmonline.com/2016/04/13/economicsmobile-money-financial-inclusion-bank-ghanaforefront-regulations/

7. Blay, P. (2016). Mobile money transactions hit over GH4600m in June 2016. Ghana News.

8. Retrieved 20 March 2017, from http://citifmonline.com/2016/08/10/mobile-moneytransactions-hit-over-gh\%C2\%A2600m-in-june2016/

9. Mutinda, A. (2014). The Effect of Mobile Phone Based Money Transfers on the Financial Performance of Small and Medium Enterprises in Nairobi County, Kenya (Post-Graduate). University of Nairobi.

10. Abong'o Otieno Maurice 2016, service quality and competitiveness in mobile money firms, school of business, university of Nairobi, Kenya.

11. USSAID 2010, transactional efficiency. ussaid.gov 